\title{
Investigation of the wound healing effects of chitosan on FGFR3 and VEGF Immunlocalization in experimentally diabetic rats
}

\author{
Z. Deniz Sahın Inan ${ }^{1, *}$, Serpil Unver Saraydın ${ }^{1}$ \\ ${ }^{1}$ Department of Histology and Embryology, Faculty of Medicine, Cumhuriyet University, Sivas, Turkey \\ Email address: \\ zeynepdnz@hotmail.com (Z. D. S. Inan)
}

\section{To cite this article:}

Z. Deniz Sahın Inan, Serpil Unver Saraydın. Investigation of The Wound Healing Effects of Chitosan on FGFR3 and VEGF Immunlocalization in Experimentally Diabetic Rats. International Journal of Biomedical Materials Research. Vol. 1, No. 1, 2013; pp. 1-8. doi: 10.11648/j.ijbmr.20130101.11

\begin{abstract}
Chitosan is a naturally occurring substance that stimulates correct deposition, assembly and orientation of collagen fibres in extracellular matrix components in wounds and promotes migration of inflammatory cells. Fibroblast growth factor (FGF) is one of the most important growth factors playing crucial roles in angiogenesis and wound healing. Biologically, it acts via binding to the cellular surface receptors. FGFR3 is one of the most important receptors. Therefore the aim of the present study was to investigate, histologically and histochemically, the effect of chitosan on wound healing in experimentally diabetic rats divided into four groups. When compared to the diabetic and the control groups, chitosan group had more inflammatory cells, endothelial cells, newly formed blood vessels and reticular - collagen fibres in the wound healing area from the third day of operation.Moreover, in Chitosan Group, stronger VEGF and FGFR3 immunolocalizations were evident and all steps of wound healing process were more regular. FGFR3 antibody used in this study had been tested only on diabetic wound healing. In conclusion, we have concluded that application of chitosan was essential to accelarate wound healing process in diabetic patients.
\end{abstract}

Keywords: Diabetes, Wound Healing, Chitosan, VEGF, FGFR3

\section{Introduction}

Diabetes mellitus is a chronic hyperglycaemic disorder (1).The prevalence of diabetes has increased tremendously and diabetic complications have become a serious health concern worldwide.Impaired-wound healing is one of these complications $(2,3,4)$.Lack of cellular and molecular signals required for normal wound-repair process such as angiogenesis, granulation tissue formation, epithelization, and remodelling may be the major factors in poor wound healing in diabetes mellitus (3-7).Animal models are useful in studying early changes in diabetes.It has been observed that streptozotocin or alloxan might destroy $\beta$ cells (8).

The healing of a wound requires a well-orchestrated integration of complex biological and molecular events of cell migration, proliferation, and extracellular matrix (ECM) deposition (9).Each phase is modulated by a vast array of cytokines and growth factors, which form an elaborate communication network co-ordinating the healing process. New understandings in the complexities of wound healing, and particularly the role of growth factors, are enabling clinicians to manage superficial wounds such as skin flaps and even the most difficult-to-heal wounds more effectively, but are deficient in diabetic wounds (3, 5-7). Multiple factors can lead to impaired wound healing in diabetic animals and patients. One of the important factors is that diabetic animals and patients do not produce enough growth factors (vascular endothelial growth factor; VEGF, fibroblast growth factor; FGF) and growth factor receptors (fibroblast growth factor receptor 3; FGFR3) (10-12).

Biomaterials are mostly polymers and are used in artificial organ production in contemporary medicine. The other areas for hydrogel usage are artificial tendon production, as bioadhesives in wound repair, as artificial kidney membrans, as artificial skin and biomaterial in plastic surgery. There are many monomers used in biomaterial production. In our previous studies, we investigated whether some monomers used in biomaterial production such as acrylamide, metacrylamide, $\mathrm{N}$-isopropylacrylamide, acrylic acid, 2-hydroxyethyl methacrylate, 1-vinyl-2-pyrrolidone and 
ethylene glycol had cytotoxic effects and induced apoptosis or not spinal cord. Immunolocalization of glial fibrillary acidic protein (GFAP) was olso determined, and it was evaluated by using semi-quantitative morphometrical techniques. The cytotoxicity of monomers on cultured fibroblastic cell lines was also examined in vitro (13-16). Chitosan, which is a poly D-glucosamine, is a deacetylated derivative of chitin (17).Chitosan and its oligomers are well known for their interesting biological properties which have led to various applications (17-20). Chitosan stimulate correct deposition, assembly and orientation of collagen fibers in extracellular matrix components in wounds.Moreover, histological findings indicate that chitosan membrane stimulates migration of inflammatory cells such as polymorphonuclear leucocytes, macrophages and fibroblasts.Thus it promotes granulation and cellular organization (17, 21-23).

Vascular endothelial growth factor (VEGF) is a multifunctional growth factor produced by endothelial cells, fibroblasts, smooth muscle cells, trombocytes, neutrophils and macrophages.Its function is to elicit proliferation, migration and differentiation of the said cells (24-26).Studies on wound healing process in experimentally diabetic animals have shown that several growth factors, including VEGF, are dramatically decreased (27-29).It has been suggested that administration of VEGF-A via protein or gene transfer methods increases granulation tissue formation, angiogenesis and matrix deposition in experimentally diabetic mice (27).

Fibroblast growth factor (FGF) demonstrates strong mitogenic properties in fibroblasts, osteoblasts, smooth muscle cells, endothelial cells, chondrocytes and melanocytes (27-30).It is one of the most important growth factors playing crucial roles in embryonic development, angiogenesis and wound healing.Biologically, it acts via binding to the cellular surface receptors belonging to the tyrosine kinase receptor family. Four of such surface receptors (FGFR 1-4) have been identified up until now (31-33).It has been clearly demonstrated in previous studies that FGFR3 is localized in the suprabasal region of epidermis, in the inner epidermal root sheat of hair follicles, in the smooth musle cells of blood vessels of the normal skin tissue whereas FGFR3 is immunolocalized in the suprabasal and basal layers of epidermis, around the blood vessels of the granulation tissue, in fibroblasts and inflammatory cells of the skin during wound healing process (33). However, the number of histopathological studies on VEGF immunolocalization is still limited while there exist no studies on FGFR-3 in wound healing process in diabetic subjects.

Therefore the aim of the present study was to evalute immunolocalizations of vascular endothelial growth factor (VEGF) and fibroblast growth factor receptor-3 (FGFR-3) in chitosan treated normal and experimentally diabetic rat skin during wound healing process and to study contribution of chitosan on wound healing process in diabetic conditions.

\section{Materials and Methods}

\subsection{Animals}

In the present study, 51 Wistar albino rats reared in the Experimental Animal Laboratory, Cumhuriyet University, Sivas, Turkey and weighing 250-300 g were used.Animals were divided into four groups. While the control group had 6 animals, other groups had 15 animals all of which were fed with food and tap water ad libitum.All animals were treated under the guidance of Local Ethics Committee of Experimental Animals, Cumhuriyet University Sivas, Turkey. All the treatment procedures employed in the present study were approved by the same committee too.

\subsection{Experimental Groups:}

An incision was made on the back of each animal in all groups.

Diabetic + Chitosan Group (DC) (n=15): Chitosan (Sigma, USA) was applied on the incision area every day.

Diabetic + Acetic Acid Group (DA) n=15): Only acetic acid was applied on the incision area every day.

Diabetic + Control Group (DO) $(\mathbf{n}=15)$ : Citrate buffer was applied on the incision area every day.

Control Group (C) $(\mathbf{n}=\mathbf{6})$ : Diabetes was not induced and betadin was applied on the incision area every day.

\subsection{Experimental Diabetes Induction Procedure}

Rats were not fed for overnight and and their blood glucose levels were measured in the following morning (Lever Check TD-4222). Those having a blood glucose level between $80-100 \mathrm{mg} / \mathrm{dl}$ were regarded as non-diabetic.In order to induce diabetes mellitus, rats of either sex were given a single dose of $60 \mathrm{mg} / \mathrm{kg}$ streptozotocin (STZ) in $0.1 \mathrm{M}$ citrate buffer,pH: 4.5, (Sigma Chemical Co., St Louis Missouri, USA) intraperitoneally $(34,35)$. Fourty eight hours after STZ injection, blood glucose levels were measured in samples obtained from the tail veins.Animals having a blood glucose levels above $250 \mathrm{mg} / \mathrm{dl}$ were regarded as diabetic.Rats had free access to food and water after STZ administration.

\subsection{Preparation of Chitosan}

In order to prepare $0.8 \%$ Chitosan solution, $1 \mathrm{~g}$ Chitosan was dissolved in $100 \mathrm{cc} 1 \%$ acetic acid and mixed for a few hours (36).The solution was calibrated to have a $\mathrm{pH}$ of 5.5. Solution was kept under UV light overnight for sterilization and to avoid bubbles.At the end of those processes, a sterile gel Chitosan was obtained to use in the experiments.

\subsection{Surgical Procedures}

All the animals received intramuscular injections of 90 $\mathrm{mg} / \mathrm{kg}$ ketamine hydrochloride and $3 \mathrm{mg} / \mathrm{kg}$ xylazine hydrochloride into the left front leg muscles. The rats were anesthesized but allowed to breath spontaneously during the surgical procedure. In order to prevent postoperative 
pain, $4 \mathrm{mg} / \mathrm{kg}$ rimadyl was injected subcutaneously for 3 days.Using a surgical blade No. 10, two cm long full thickness incisions (37) were made at the back of rats. The wounds were not closed throughout the experiments.Chitosan, acetic acid and betadine were applied to the incision area every day and on the 3rd, 7th and 14th days after operation. 5 animals from each group were sacrificed by injecting a high-dose $(200 \mathrm{mg} / \mathrm{kg})$ sodium pentabarbital intraperitoneally.Tissue samples were obtained from the incision area to conduct light microscope and immunohistochemial investigations.

\subsection{Light Microscopy}

Skin samples obtained from the wound area were fixed in $10 \%$ buffered neutral formaline for 48 hours and blocked in paraffin after routine histological dehydration procedures.For immunohistochemical investigations, two three $\mu \mathrm{m}$ thick tissue sections were taken by a Leica RM 2125 RT microtome.Sections were stained immunohistocemically for VEGF and FGFR3 and convenient fields of views were photographed using Olympus BX51 (Tokyo, Japan) photomicroscope.

\subsection{Immunohistochemistry}

For immunohistochemical staining, the deparaffinized and rehydrated tissue sections were inactivated using endogenous peroxidase by incubation in $3 \% \mathrm{H} 2 \mathrm{O} 2$ for 10 minutes. To recover antigen, these sections were put into EDTA solution ( $\mathrm{pH} 8.5)$ and heated in microwave oven twice.Slides were then washed in PBS (pH7.2-7.6) twice.Non-specific binding sites were blocked in Ultra V Block(Lab vision, USA) solution for 20 minutes. After the redundant liquid was discarded, sections were incubated in primary antibodies (VEGF Ab-1 and FGFR3, Lab Vision USA) at room temperature for 1 hour and washed in PBS.Slides were then incubated in biotinylated secondary antibody (Lab Vision, USA) for 20 minutes and washed in PBS which was followed by incubation in streptavidinHRP (Lab Vision, USA) for 20 minutes and by washing in PBS.Antibody binding sites were visualized by incubation with an AEC chromogen (Lab Vision, USA) solution.Slides were counterstained for 1 minute in hematoxylin and then dehydrated in sequential ethanol series for sealing and microscopic observations.

\section{Results}

Histological features stained immunohistochemically, were evaluated semi-quantitatively and the results are shown in Tables 1 and 2.In Chitosan Group, immunolocalization of vascular endothelial growth factor (VEGF) (Table 1, Fig. 2,4,6) revealed a strong expression in the epithelium close to the wound region, in the healing area, in the sebaceous glands and around the blood vessels on the 3rd day; however, its immunolocalization decreased gradually on the 7 th day and it was rather weak on the 14th day when compared to the other groups.Immunohistochemical staining by FGFR3 (Table 2, Fig. 8,10,12) in Chistosan Group revealed a very strong expression on the 3 rd day, a rather weak expression on the 7 th day and a strong expression on the 14th day in the epithelium close to the wound region and around the hair follicles, sebaceous glands and blood vessels when compared to the other groups.

\section{Discussion}

Diabetes is a chronic metabolic disease affecting the majority of the world population. While the number of people having diabetes for several reasons has been increasing, complications observed in diabetes have been increasing too (1-4). One of the most important complications seen in diabetic patients is the impaired wound healing $(38,39)$.

At the present, several subsidiary biomaterials have been used for a better wound healing therapy and chitosan is one of them.Chitosan is a natural polymer made by chitin.Chitin is the most abundant polymer after cellulose and it is present in the cell wall of sea shells and mushrooms $(17,18,40)$.Chitosan, a biodegradable and biocompatible polymer, is an important and indispensable biomaterial in pharmacology and in medicine since it is nontoxic and causes no allergy or irritation. At the same time, through accelarating the wound and bone healing, Chitosan is a haemostatic, antibacterial and antifungal immune system stimulant (19-21, 41).

Wound healing process occurs around three main events; haemostasis and inflammation, new tissue formation and remodelling $(30,42,43)$. These events occur not in a particular order but in a complicated manner (30, 4244).During wound healing process, angiogenic growth factors such as vascular endothelial growth factor (VEGF), placental growth factor (PGF), acidic and basic fibroblast growth factor 1 and 2 (FGF1 and 2), fibroblast growth factor 3 and 4 (FGF3 and 4), FGF receptors, transforming growth factor $\alpha-\beta$ (TGF $\alpha-\beta)$, epidermal growth factor (EGF), hepatocyte growth factor (HGF), angiogenin, platelet derived growth factor (PDGF, granulocyte colony stimulating factor (GCSF), interleukin 8 (IL 8), tumour necrosis factor- $\alpha$ (TNF- $\alpha$ ) and proliferin are important (45).

Vascular endothelial growth factor (VEGF) is a member of multifunctional growth factor family and has specific effects especially on endothelial cells.It binds to its receptors with a complex system thus regulates blood vessel formation $(24-26,45)$. During wound healing process, vascular endothelial growth factor (VEGF) is produced by several cells such as endothelial cells, fibroblasts, smooth muscle cells, trombocytes, neutrophils and macrophages. Its functions are proliferation, migration and differentiation of endothelial cells (23-25).In a previous study, VEGF immunoreactivity and its relationship with angiogenesis has been described in glioma cells (45-47). Recent studies have shown that VEGF may have effects on collagen deposition and epithelial formation (48).In the first phase of wound healing, VEGF stimulates the coagulant factors in 
the endothelial cells. Therefore, the trombocyte accumulation and adhesion occur (46-48).For blood vessel formation, immunolocalization of vascular endothelial growth factor is increased in inflammatory cells during inflammation period of the wound healing while it is also observed in fibroblasts, endothelial cells and macrophages during the following phases of the wound healing process (4648).Blood vessel formation (angiogenesis) occurs on the 3rd day of the wound healing process.In order to attract metabolites and oxygen to the healing region, the number of capillaries increases in the granulation tissue (48, 49).Previous studies have clearly shown that keratinocytes around the wound, fibroblasts and macrophages in the wound region, macrophages in the wound region and growing blood vessels start to produce VEGF whose secretion reaches its maximum level on the third and the seventh days $(49,50)$.In the present study, VEGF immunolocalization was strong on the $3 \mathrm{rd}$ day while it gradually decreased on the 7 th and 14th days in the control group.Previous studies have demonstrated that VEGF production is rather high between the 3rd and 7th days in wound healing area (48-50).Formation of granulation tissue, which contains fibroblasts, macrophages and endothelial cells all of which are essential for VEGF secretion, occurs on the third and seventh days of the wound healing process (50).Findings of the present study revealed that VEGF expression was low on the 3rd day, moderate on the 7th day and strong on the 13th day in the diabetes+control and in the diabetes+acetic acid groups.Like all other growth factors, VEGF production is suppressed in diabetic conditions $(27,28)$.VEGF secretion form keratinocytes and fibroblasts has been shown to be decreased in in diabetics (27). Altavilla et al. have suggested that oxydative stress causes impairments in VEGF secretion and regulation in diabetic patients (50).In a histopathological study on diabetic mice, Komesu et al. showed that the onset of inflammation phase was delayed in diabetic animals and chronic inflammation findings lasted longer in samples collected on the 1st, 3rd and 7th days (1).In our study, VEGF immunolocalization was low in the diabetes+control and in diabetic+acetic acid groups on the $3 \mathrm{rd}$ and the 7 th days.However, VEGF immunolocalization was very strong on the 3 rd day, strong on the 7 th day and moderate on the 14th day in diabetic+chitosan group.Histopathological findings of previous studies have revealed that leukocytes and macrophages reach wound area faster in chitosan treated animals when compared to the controls $(21-23,51)$.Therefore, it can be suggested that chitosan might stimulate inflammatory cells and their growth factors in the wound area during the early phases of the wound healing process.In fact, chitosan attracts inflammatory cells and VEGF to the wound healing area during the early stages of the wound healing process (21, 51).Ueno et al. have suggested that chitosan accelarates granulation tissue formation (21).At the same time, chitosan activates fibroblasts in the granulation tissue, caused them to proliferate and accelerates extracellular matrix production (23). Therefore, the present study suggests that chitosan might accelerate the wound healing by increasing VEGF secretion despite the negative effects of diabetes.

It has been suggested that acidic fibroblast growth factor (aFGF or FGF1) and basic fibroblast growth factor (bFGF or FGF2) are potential angiogenic factors in diabetics just like VEGF (22-24). Fibroblast growth factor receptors also play key roles in the wound healing process.Four types of FGF receptors have been found in epidermal layers, muscles, blood vessels, fibroblasts, hair follicles, granulation and inflammation tissues of normal and wounded tissues during the wound healing process $(31-33,52)$. Takenaka et al. have evaluated normal and burned human tissue samples and suggested that FGFR1 and FGFR3 have strong expressions in the first stage of the healing process while these receptors has weaker expressions following the granulation tissue formation (33). On the other hand, they have also suggested that when FGFR1 and FGFR3 have weak immunolocalizations, FGFR2 and FGFR4 have strong expressions along with moderate FGFR1 and FGFR3 expressions towards the final stage of the healing process (33).However, there are no data on the FGFR3 expression in diabetic wound healing process.In the present study, the FGFR3 immunolocalization in the basal layer of epidermis, in the epidermal root sheath of hair follicles, around the blood vessels, in sebaceous glands and in the healing region were very strong on the 3rd day, moderate on the 7 th day and strong on the 14th day in Chitosan Group when compared to the control and the other groups.Chitosan is very affective on the secretion of growth factors from the cells in all stages of wound healing process $(17-23,51)$.A similar finding, namely strong expression of FGFR3 in the wound healing area, was found in our study stoo. The present study showed that the healing process of full thickness incisions made in diabetic rats was affected positively when chitosan was applied. Besides having antibacterial and antifungal properties, Chitosan is a cheap and easily obtained natural polymer.Wound healing is a complex process including number of cells and growth factors.Due to being very a expensive and time consuming process, treatment of wounds in diabetic patients is very difficult. By demonstrating VEGF and FGFR3 expressions in the wound healing regions, the present study has clearly shown that application of chitosan, with its positive effects on wound healing process, helps to overcome the above mentioned difficulties.

Table 1. Semi-quantitative comparison of VEGF expressions on the $3^{\text {rd }}, 7^{\text {th }}$ and 14 day in the Control (C),Diabetic Acetic Acid+Diabetic Control $(D A+D O)$ and ChitosaGroups $(D C)$.

\begin{tabular}{llll}
\hline VEGF & C & DA+DO & DC \\
\hline $\mathbf{3}^{\text {rd }}$ Day & +++ & ++ & ++++ \\
$\mathbf{5}^{\text {th }}$ Day & +++ & +++ & ++++ \\
$\mathbf{1 4}^{\text {th }}$ Day & ++ & +++ & ++ \\
\hline
\end{tabular}

+++++ very strong, ++++ strong, +++ moderate, ++ low, +very low 
Table 2. Semi-quantitative comparison of FGFR3 expressions on the $3^{\text {rd }}$, $7^{\text {th }}$ and $14^{\text {th }}$ days in the Control (C), Diabetic Acetic Acid+Diabetic Control $(D A+D O)$ and Chitosan Groups $(D C)$.

\begin{tabular}{llll}
\hline FGFR3 & C & DA+DO & DC \\
\hline 3rd Day & +++ & + & +++++ \\
5th Day & ++ & +++ & ++ \\
14th Day & +++ & +++ & ++++ \\
\hline
\end{tabular}

+++++very strong, ++++ strong, +++ moderate, ++ low, +very low

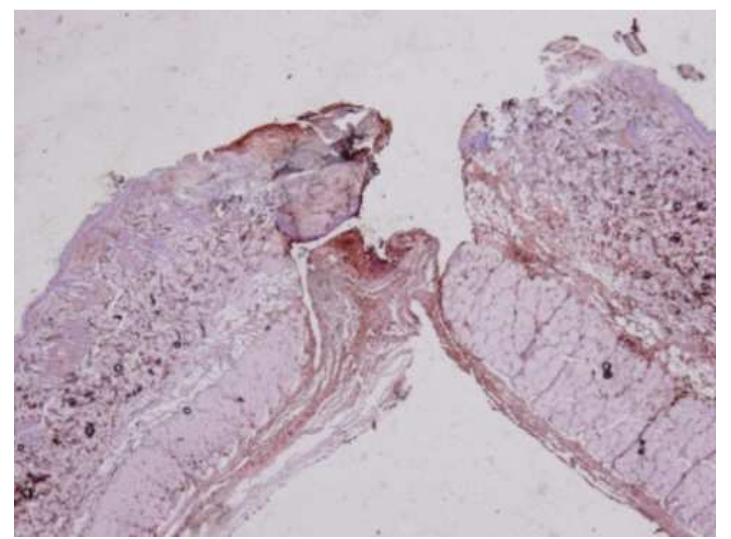

Figure 1. Control Group, on days 3 (X4),VEGF immunolocalization in the wound healing region.

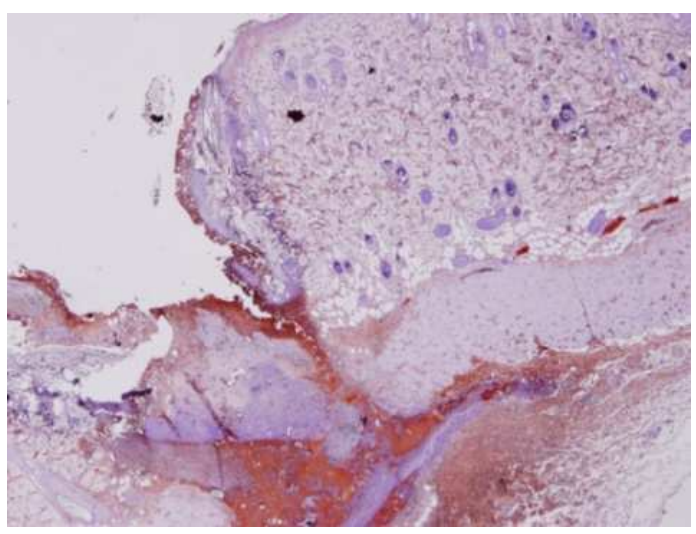

Figure 2. The VEGF immunolocalization on days $3(X 4)$, in the incision made and chitosan application group (DC).

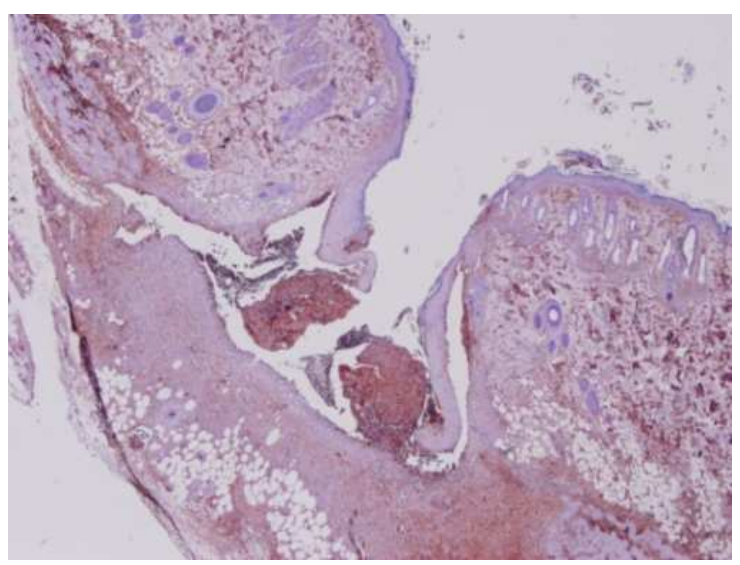

Figure 3. Control Group, on days 7 (X4),VEGF immunolocalization in the wound healing region.

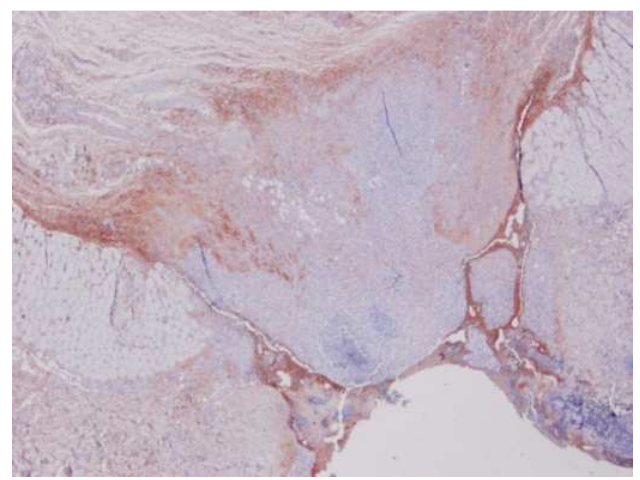

Figure 4. The VEGF immunolocalization on days 7 (X4), in the incision made and chitosan application group (DC).

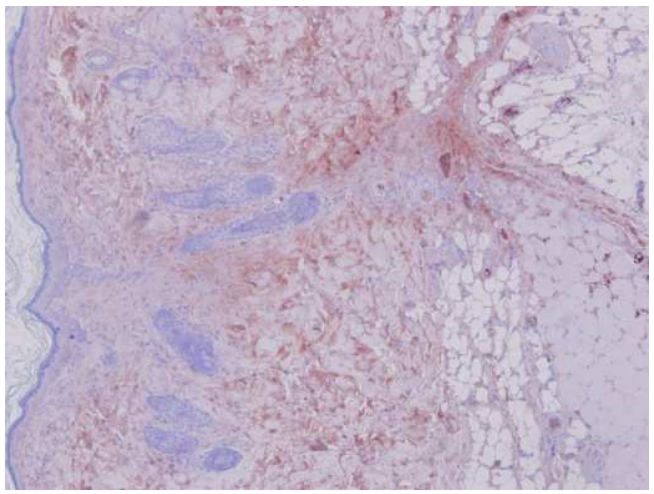

Figure 5. Control Group, on days 14 (X4),VEGF immunolocalization in the wound healing region.

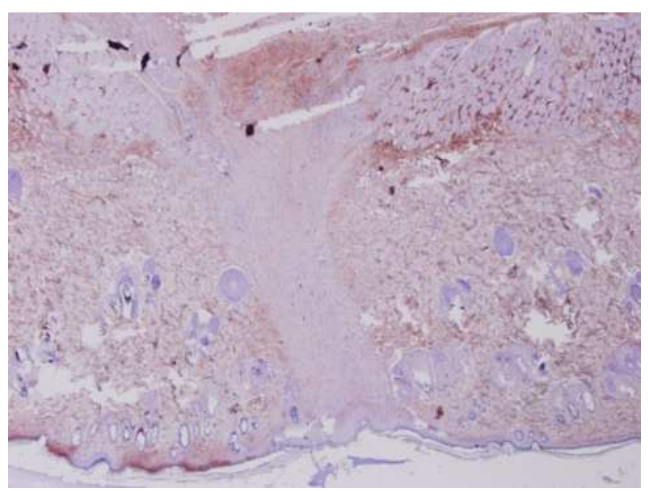

Figure 6. The VEGF immunolocalization on days 14 (X4), in the incision made and chitosan application group (DC).

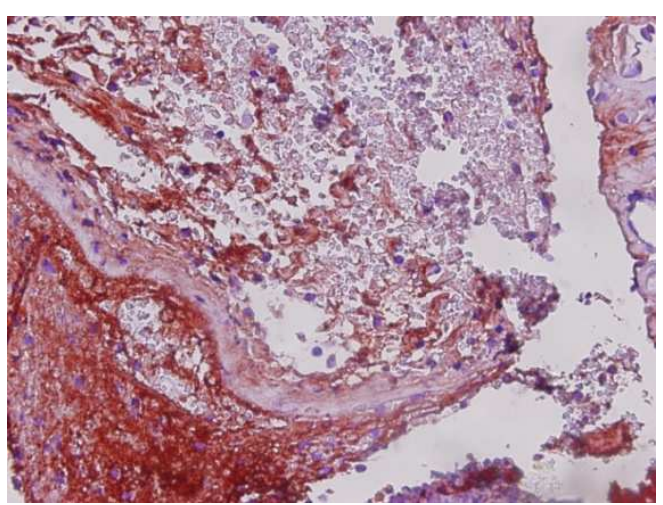

Figure 7. Control Group, on days 3 (X40), FGFR3 immunolocalization in the wound healing region. 


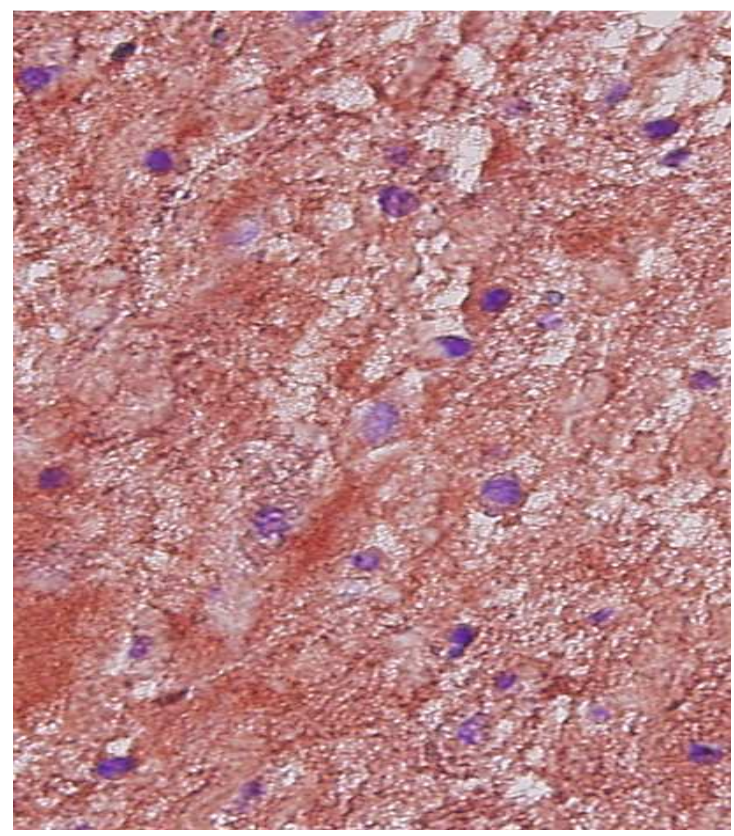

Figure 8. The FGFR3 immunolocalization on days 3 (X40), in the incision made and chitosan application group (DC).

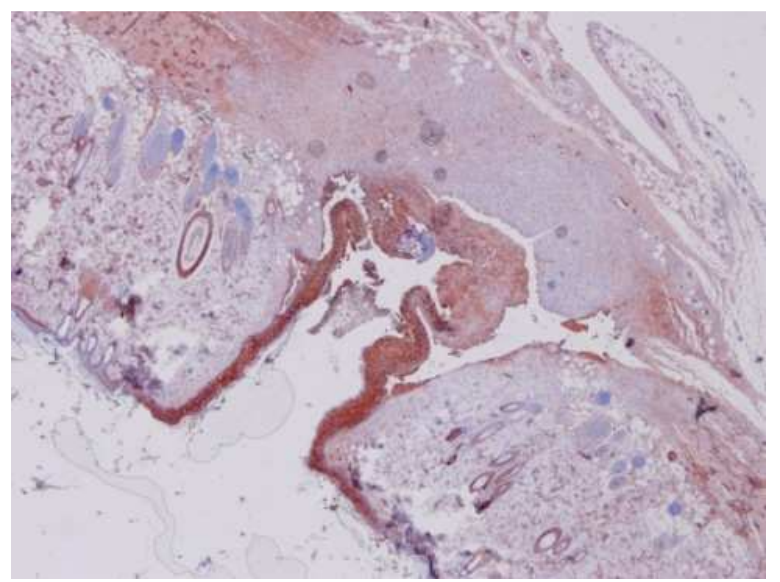

Figure 9. Control Group, on days 7 (X4),FGFR3 immunolocalization in the wound healing region.

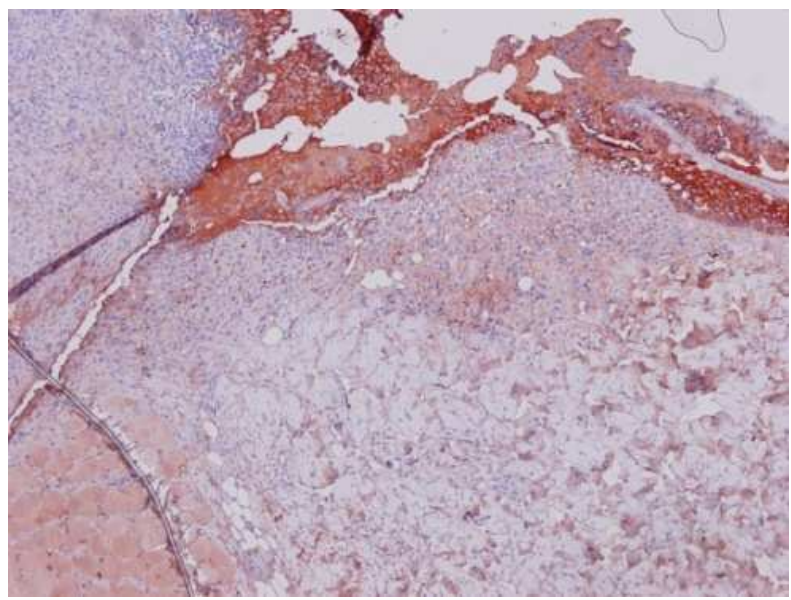

Figure 10. The FGFR3 immunolocalization on days 7 (X10), in the incision made and chitosan application group (DC).

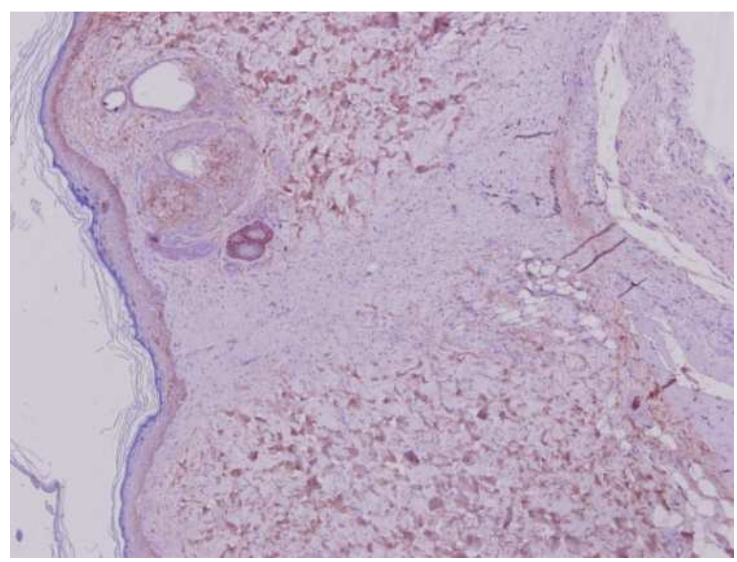

Figure 11. Control Group, on days 14 (X10),FGFR3 immunolocalization in the wound healing region.

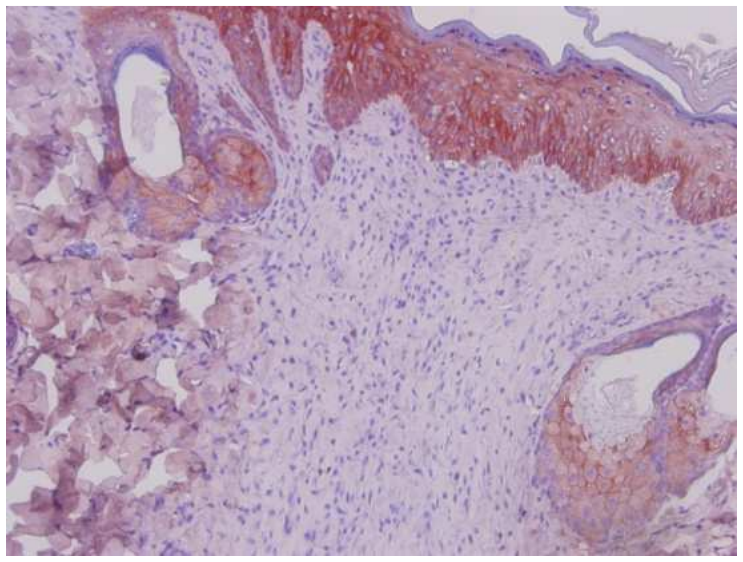

Fifure 12. The FGFR3 immunolocalization on days 14 (X20), in the incision made and chitosan application group (DC).

\section{Acknowledgement}

The authors wish to warmly thank to Dr.Eray BULUT for his critical appraisal of the manuscript. This study was carried out in the Research Laboratories of the Faculty of Medicine Cumhuriyet Universityin Sivas, Turkey and was supported by the Cumhuriyet Univercity Research Foundation.

\section{References}

[1] Komesu MC, Tanga MB, Buttros KR, et al (2004)Effects of acute diabetes on rat cutaneous wound healing. Pathophysiology 11:63-67.

[2] Van Belle TL, Coppieters KT, Von Herrath MG (2011) Type 1 diabetes: etiology, immunology and therapeutic strategies. Physiol Rev. 91(1):79-118.

[3] Brem H, Tomic-Canic M (2007) Cellular and molecular basis of wound healing in diabetes. The Journal of Clinical Invest.117 (5):1219-1222.

[4] Pavlovic MD, Milenkovic T, Dinic M, et al (2007) The prevalence of cutaneous manifestations in young patients with IDDM. Diabetes Care 30(8):1964-1967. 
[5] Blakytny R, Jude EB, Martin G, et al (2000) Lack of insulin-like growth factor 1 (IGF1) in the basal keratinocyte layer of diabetic skin and diabetic foot ulcers. Journal of Pathology 190(5):589-59.

[6] Jude EB, Blakytny R, Bulmer J, et al (2002) Transforming growth factor-beta 1, 2, 3 and receptor type I and II in diabeticfoot ulcers. Diabetic Medicine 19(6):440-447.

[7] Blakytny R, Jude E (2006) The molecular biology of chronic wounds and delayed healing in diabete. Diabetic Medicine 23(6):594-608.

[8] Szkudelski T (2001) The mechanism of alloxan and streptozotocin action in B cells of the rat pancreas. Physiol Res. $50: 536-46$

[9] Baum CL,Arpey J (2005) Normal cutaneous wound healing: clinical Correlation with Cellular and Molecular Events. Dermatolologic Surgery 31(6):674-686.

[10] Cupp CL, Bloom DC ( 2002)Gene therapy, electroporation, and the future of wound-healing therapies. Facial Plast Surg 18:53-7.

[11] Man LX, Park JC, Terry MJ et al (2005) Lentiviral gene therapy with platelet-derived growth factor B sustains accelerated healing of diabetic wounds over time. Ann Plast Surg 55:81

[12] Nagai MK, Embil JM (2003) Becaplermin: Recombinant platelet derived growth factor, a new treatment for healing diabetic foot ulcers. Expert Opin Biol Ther 2:2-11.

[13] Saraydin D, Koptagel E, Unver-Saraydin S, Karadag E, Guven O (2001). In vivo biocompatibility of radiation induced acrylamide and acrylamide/maleic acid hydrogels. Journal of Materials Science 36(10):2473-2481.

[14] Saraydin D, Unver-Saraydin S, Karadag E, Koptagel E,Guven O (2004). In vivo biocompatibility of radiation crosslinked acrylamide copolymers. Nuclear Instruments and Methods 217:281-292.

[15] Unver-Saraydin S, Bulut HE, Ozüm Ü, İnan Sahin ZD, Polat ZA, Yalman Y, Saraydin D (2011). Evaluation of the cytotoxic effects of various monomers in vitro also their effects apoptosis and GFAP immunolocalization in rat spinal cord in vivo. HealthMED 5(1):17-28.

[16] Unver-Saraydin S, Saraydin D (2011). Histopathological effect characteristics of various biomaterials and monomers used in polymeric biomaterial production in biomaterials. Physics and Chemistry, edited by: Rosario Pignatell In Tech.

[17] Illum L (1998). Chitosan and its use as a pharmaceutical excipient. Pharm Res 15:326-1331.

[18] Ravikumar MNV (2000) A review of chitin and chitosan applications. Reactive and Functional Polymers 46:1-27.

[19] Shigemasa Y, Minami S (1995) Applications of chitin and chitosan for biomaterials. Biotechnology and Genetic Engineering Reviews 13:383-420.

[20] Singla AK, Chawla M (2001)Chitosan: some pharmaceutical and biological aspects-an update J. Pharm. Pharmacol 53:1047-1067.
[21] Ueno H, Mori T, Fujinaga T (2001) Topical formulations and wound healing applications of chitosan Adv. Drug. Del. Rev 52:105-115.

[22] Okamoto Y, Shibazaki K, Minami S et al (1995) Evaluation of chitin and chitosan on open wound healing in dogs. J. Vet. Med. Sci. 57:851-854.

[23] Alemdaroglu C, Degim Z, Celebi N et al (2006) An investigation on burn wound healing in rats with chitosan geL formulation containing epidermal growth factor. Burns 32: 319-327.

[24] Gavard J, Gutkind JS (2006)VEGF controls endothelial-cell permeability by promoting the beta-arrestin-dependent endocytosis of VE-cadherin. Nat Cell Biol. 8:1223-1228.

[25] Barkovic A, Sirois MG (2007)Vascular permeability induced by VEGF family members in vivo: Role of endogenous PAF and NO synthesis. J Cell Biochem. 100:707-210.

[26] Bao P, Kodra A,Tomic-Canic BAMet al (2008) The role of vascular endothelial growth factor in wound healingdoi: $10.1016 /$ j. jss. 04.023.

[27] Jazwa A, Kucharzewska P,Leja J et al (2010) Combined vascular endothelial growth factor $\mathrm{A}$ and fibroblast growth factor gene transfer improves wound healing in diabetic mice. Genetic vaccines and Therapy 8(6): 2-16.

[28] Falanga V (2005) Wound healing and its impairment in the diabetic foot. Lancet 366(9498):1736-1743

[29] Doxey DL, Ng MC, Dill RE, Iacopino AM (1995) Plateletderived growth factor levels in wounds of diabetic rats. Life Sci. 57(11):1111-1123

[30] Turan M, Saraydin US, Bulut E et al (2004)Do vascular endothelial growth factor and basic fibroblast growth factor promote phenytoin's wound healing effect in rat? An immunohistochemical and histopathologic study. Dermatol Surg. 30:1303-1309.

[31] Suhardja A, Hoffman H (2003) Role of growth factors and their reseptors in proliferation of microvascular endothelial cells. Microscopy Research and Technique 60:70-75.

[32] Hughes SE (1997) Differantial expression of the fibroblast growth factor receptor (FGFR) multigene family in normal human adult tissues. J Histochem Cytochem.45(7):10051019.

[33] Takenaka H, Yasuno H, Kishimoto S (2002) Immunolocalization of fibroblast growth factor receptors in normal and wounded human skin. Arch Dermatol Res. 294:331-338.

[34] Karabay G, Zağyapan R, Take G (2006) Streptozotosinle oluşturulan diabetin sıçan periferik sinirleri üzerine etkisinin elektron mikroskobik incelenmesi. Uludağ Üniversitesi Tip Fakültesi Derg. 32(3):77-81.

[35] Saeed MK, Deng Y, Dai R (2008) Attenuation of biochemical parameters in streptozotocin-induced rats by oral administration of extracts and fractions of Cephalotaxus sinensis. J Clin Biochem Nutr. 42:21-32.

[36] Chen XG, Liu CS, Liu CG et al (2006) Preparation and biocompatibility of chitosan microcarriers as biomaterial. Biochemical Engineering Journal27:269-274. 
[37] Atiba A, Ueno H (2010) The effect of Aloe Vera oral administration on cutaneous wound healing in type 2 diabetic rats. J Vet Med Sci. doi:10.1292/jvms.10-0438.

[38] Brem H, Tomic-Canic M (2007) Cellular and molecular basis of wound healing in diabetes. The Journal of Clinical Invest. 117(5):1219-1222

[39] Pavlovic MD, Milenkovic T, Dinic M et al (2007)The prevalence of cutaneous manifestations in young patients with IDDM.Diabetes Care 30(8):1964-1967.

[40] Nigalaye AG, Adusumuli P, Bolton S (1990) Investigation of prolonged drug release from matrix formulations of chitosan. Drug Dev Ind Pharm. 16:449-467.

[41] Rao SB and Sharma CP (1997)Use of chitosan as a biomaterial: Studies on its safety and hemostatic potential. J Biomed Mater Res. 34:21-28.

[42] Acosta JB, Barco DG, Vera DC et al (2008) The proinflammatory environment in recalcitrant diabetic foot wounds.International Wound Journal 5:530-630.

[43] Sabine AE, Thomas K, JeffreyMD (2007)Inflammation in wound repair: Molecular and cellular mechanisms. Journal of Investigative Dermatology 127:514-525.

[44] Martin P and Leibovich S J (2005)Inflammatory cells during wound repair: the good, the bad and the ugly. Trends Cell Biol. 15:599-607.

[45] Olsson AK, Dimberg A, Kreugeret al (2006) VEGF receptor signalling-in control of vascular function. NatRev Mol Cell7:359-564.
[46] Banks RE, Forbes MA, Kinsey SE et al (1998) Release of the angiogenic cytokine vascular endothelial growth factor (VEGF) from platelets: Significance for VEGF measurements and cancer biology. Br J Cancer 77:956-960.

[47] Miyagami M, Katayama Y (2005) Angiogenesis of glioma: evaluation of ultrastructural characteristics of microvessels and tubular bodies (Weibel-Palade) in endothelial cells and immunohistochemical findings with VEGF and p53 protein. Med Mol Morphol. 38:36-42.

[48] Nogam M, Hohi T, Kinoshita M et al (2007) Vascular endothelial growth factor expression in rat skin incision wound. Med Mol Morphol. 40:82-87.

[49] Nissen NN, Polverini PJ, Koch AE et al (1998) Vascular endothelial growth factor mediates angiogenic activity during the proliferative phase of wound healing. Am J Pathol. 152:1445-1450.

[50] Altavilla D, Saitta A, Cucinotta D et al (2001) Inhibition of lipid peroxidation restores impaired vascular endothelial growth factor expression and stimulates wound healing and angiogenesis. Diabetes 50:667-670.

[51] Ueno H, Yamada H, Tanaka I et al (1999). Accelerating effects of chitosan for healing at early phase of experimental open wound in dogs. Biomaterials 20:1407-14.

[52] Komi-Kuramochi A, Kawano M, Oda Y et al (2005) Expression of fibroblast growth factors and their receptors during full-thickness skin wound healing in young and aged mice. Journal of Endocrinology 186:273-289. 